\title{
Application of a computer dairy model on-farm
}

\section{C.A. LEWIS' and B. GARRITY ${ }^{2}$ \\ 'Agriculture New Zealand, Masterton ${ }^{2}$ Farmer, Tui Milk Products Director, Greytown}

Keywords: computer, dairy farm, forecast, gross margin, model, simulator

For Mr Barry Garrity, Carterton dairy farmer, the spring of 1992 brought a very challenging decision-making process.

A computerised simulator (model) of the physical functions of his property had been in use since October 199 1. As a high stocking rate, high performance farm the next step in improving profitability was being sought. The simulator provided a means of reviewing performance, searching out means of more efficient use of pasture and overcoming the limitations to increased production.

The software (UDDER) models grass growth and animal performance for an actual season with a gross margin used to reflect the financial component. In this case base data were derived from the 1990191 season, a record year for the property.

Analysis showed some key limitations: the stocking rate could be a little high (3.8 cows/ha) and as a milking platform growing 13.5 tonne of dry matter per hectare optimum production was nearly achieved via maximum pasture utilisation.

The next step would come from importing supplements, more nitrogen and greenfeed maize. Putting this information into the program forecasts were prepared for coming seasons and tested for relative profitability.

The forecast for the 1992/93 season suggested a good result: $302 \mathrm{~kg}$ of milk solids per cow or $1140 \mathrm{~kg}$ per ha - double the district average.

Included were performance targets and suggested timing for input of supplements. The farm's contract milker was included in the policy decisions and asked to monitor progress, ensuring everything stayed on track.

What followed was unexpected weather. High spring rainfall led to waterlogged soils. Pasture growth rates through September and early October were reduced by over $30 \%$ on predicted (1990/91). Pasture covers fell by $500 \mathrm{~kg}$ of dry matter per ha below target.

As the physical situation reached a critical point, major decisions had to be made. We returned to UDDER. After updating to the current status, the question was posed on how to maintain production, rebuild pasture cover, keep the cows in good condition with a minimum of expenditure.
Given the program's ability to forecast the effects physically and financially of various policy changes, a number of alternate strategies were tested. De-stocking by drying-off, once daily milking, meal feeding and increased nitrogen use were workable options within the various strategies.

The best path for recovery was at first considered drastic: to remove 60 cows (19\% of the herd), feed 22 tonnes of meal, once daily milking for 10 days and apply $118 \mathrm{~kg} / \mathrm{ha}$ of nitrogen. Yet this was required to provide an acceptable level of performance and retain viability in terms of having a reasonable pasture cover and cow condition at the end of the season.

This update showed a significant drop in production, to $260 \mathrm{~kg}$ of milk solids per cow and 976 per ha - a 15\% decrease from the original forecast with an associated $16 \%$ reduction in gross margin due to higher feeding costs. The strategy was cautiously implemented; destocking occurring progressively in late September and late October.

In April 1993 a retrospective assessment was taken of the season.

"In hindsight the weather cost us production but

UDDER gave us the best response. At the right time a confident decision was made under the pressure created by an adverse situation."

Further, UDDER had helped to motivate the contract milker. During a time of intense pressure a method of recovery could be found that outlined implementation, provided targets to gauge progress and kept up the perspective of long-term improvements in performance.

UDDER is an involved tool that demands a strong technical understanding and a working grass roots knowledge of the dairy industry. It has the capability of reviewing past seasons, forecasting opportunities in current seasons and creating long-term goals, with the emphasis placed on improved economic well-being.

By using a computer model, years of experience can be gathered in a much shorter time. If a strategy can be tested in seconds without risking capital, farmers can be encouraged to adopt "new" practices.

Mr Garrity's farm provides a working example of how a computer model can be used in day-to-day operations. It will result in timely and effective management decisions, giving meaningful feedback on physical and financial implications of changes in climate or policy. 